\title{
Estimation of Engineering Properties of Soils from Field SPT Using Random Number Generation
}

\author{
Ranjan Kumar $^{1} \cdot$ Kapilesh Bhargava $^{2,3} \cdot$ Deepankar Choudhury ${ }^{4,5}$
}

Received: 17 May 2016/Accepted: 28 September 2016/Published online: 18 October 2016

(C) Indian National Academy of Engineering 2016

\begin{abstract}
For design of foundation, engineering properties like strength and deformability characteristics of soils are very important parameters. Soil properties like cohesion, angle of friction, shear wave velocity, Poisson's ratio etc. are important for evaluation of the vibration parameter by numerical modeling of soil. In various numerical modeling software manuals, various ranges of these parameters are specified. If any of these software is used, the output results of a problem are mostly very sensitive to these input parameters. Hence, selection/estimation of proper values of these engineering properties of soil is very critical for analysis of a geotechnical engineering problem. Twelve empirical correlations of soil properties in terms of common field Standard Penetration Test (SPT)- $N$ value have been developed through random number generation technique. The usefulness of the presently developed correlations is verified by validating the correlations with
\end{abstract}

Ranjan Kumar

ranjancv42@gmail.com

Kapilesh Bhargava

kapilesh_66@yahoo.co.uk

Deepankar Choudhury

dc@civil.iitb.ac.in

1 Civil Engineering Division, Bhabha Atomic Research Centre, Mumbai 400085, India

2 Nuclear Recycle Board, Bhabha Atomic Research Centre, Mumbai, India

3 Homi Bhabha National Institute, Mumbai, India

4 Department of Civil Engineering, Indian Institute of Technology Bombay, Powai, Mumbai 400076, India

5 Academy of Scientific and Innovative Research (AcSIR), New Delhi, India experimental values available in literature, which in turn can be used for geotechnical engineering design problems.

Keywords Soil properties - Random number .

SPT N value $\cdot$ Experimental data

\section{Introduction}

Laboratory and in situ tests are conducted to estimate the strength and elastic properties of soil. Many times due to budget limitations, time constraints and other concerns, there is a tendency to discard the tests. Either data from adjacent site is considered or some correlations are used to estimate the properties. Empirical correlations have been extensively used in the past for estimations of these parameters but they are based on the selected published data/tests from different sources having inconsistency of test material, test procedure and data interpretation. The empirical relationships have also been developed in terms of field Standard Penetration Test (SPT), $N$ value. SPT $N$ value is widely used as it is an index for quick strength characterization due to its simplicity. In estimation of other parameters also, SPT $N$ value is used e.g., for estimation of shear wave velocity, bearing capacity etc. The SPT field test is most conventional test for general characterization of soil. Few correlations are available in literature in terms of SPT $N$ value. But there is no clear explanation for selection of these correlations. Development of a reliable correlation will assist the practicing engineers in case of unavailability of laboratory and in situ test results, and it will go a long way to assist practicing engineers to estimate mechanical properties of soil.

Many studies on empirical relationships have been done in the past on different soil types. Empirical relations were 
Table 1 Ranges of SPT $N$ value with cohesion for cohesive soils

\begin{tabular}{lllllll}
\hline SPT $N$ value & $>30$ & $15-30$ & $8-15$ & $4-8$ & $2-4$ & $<2$ \\
\hline Cohesion, $\mathrm{kPa}$ & 192 & $96-192$ & $48-96$ & $24-48$ & $12-24$ & 12 \\
Soil conditions & Hard & Very stiff & Stiff & Firm & Soft & Very soft \\
\hline
\end{tabular}

Data from Karol (1960)

developed between cohesion and SPT $N$ value, and between angle of friction and SPT $N$ value (Brown and Hettiarachchi 2008; Hettiarachchi and Brown 2009). Empirical correlations were developed between angle of friction and SPT $N$ value by Suzuki et al. (1993) and Hatanaka and Uchida (1996). Correlations between undrained shear strength and SPT N value were developed by Hara et al. (1974); Sivrikaya and Togrol (2006) and Kalantary et al. (2009). Recently many correlations were developed between shear wave velocity and SPT $N$ value by Hara et al. (1974), Wei et al. (1996), Miura et al. (2003), Hasancebi and Ulusay (2007), Anbazhagan and Sitharam (2010), Maheshwari et al. (2010), Akin et al. (2011), Anbazhagan et al. (2012, 2013), Sun et al. (2013), Chatterjee and Choudhury (2013) and Rao (2013). In case of soil, generalized empirical models for various blast induced parameters were developed in terms of unit weight, degree of saturation and Young's modulus of soil (Kumar et al. 2014a). Application of such data was shown by Kumar et al. (2012). Correlations of uniaxial compressive strength of rock mass with conventional strength properties were developed by Kumar et al. (2016b). The relationships in the literature are applicable for the prescribed types of soils similar to those used to develop the relationships. However, there is hardly any relationship which is applicable for wide range of soils.

This paper presents correlations which have been developed from published ranges of various soil properties. The ranges have been collected from the literature and with the help of random number generation technique, correlations have been developed in terms of SPT $N$ value. The correlations have been validated with available experimental data.

\section{Soil Parameters Required for Numerical Modeling}

Most common input soil parameters for numerical modeling in soil are unit weight $(\gamma)$, Young's modulus $(E)$, Poisson's ratio $(\mu)$, Seismic velocity $\left(v_{p}\right)$, cohesion $(C)$, angle of friction $(\varphi)$ and tensile strength. Most common rock input parameters for numerical modeling in rock are UCS $\left(f_{c}\right)$, unit weight, Young's modulus $(E)$, Poisson's ratio $(\mu)$, Seismic velocity $(c)$, cohesion $(C)$, angle of friction $(\varphi)$ tensile strength (Kumar et al. 2014b, 2015, 2016a). Once these parameters are estimated,
Table 2 Ranges of SPT $N$ value with Cohesion for intermediate soils

\begin{tabular}{llll}
\hline SPT $N$ value & $>30$ & $10-30$ & $<10$ \\
\hline Cohesion, $\mathrm{kPa}$ & 48 & $5-48$ & 5 \\
Soil conditions & Dense & Medium & Loose \\
\hline
\end{tabular}

Data from Karol (1960)
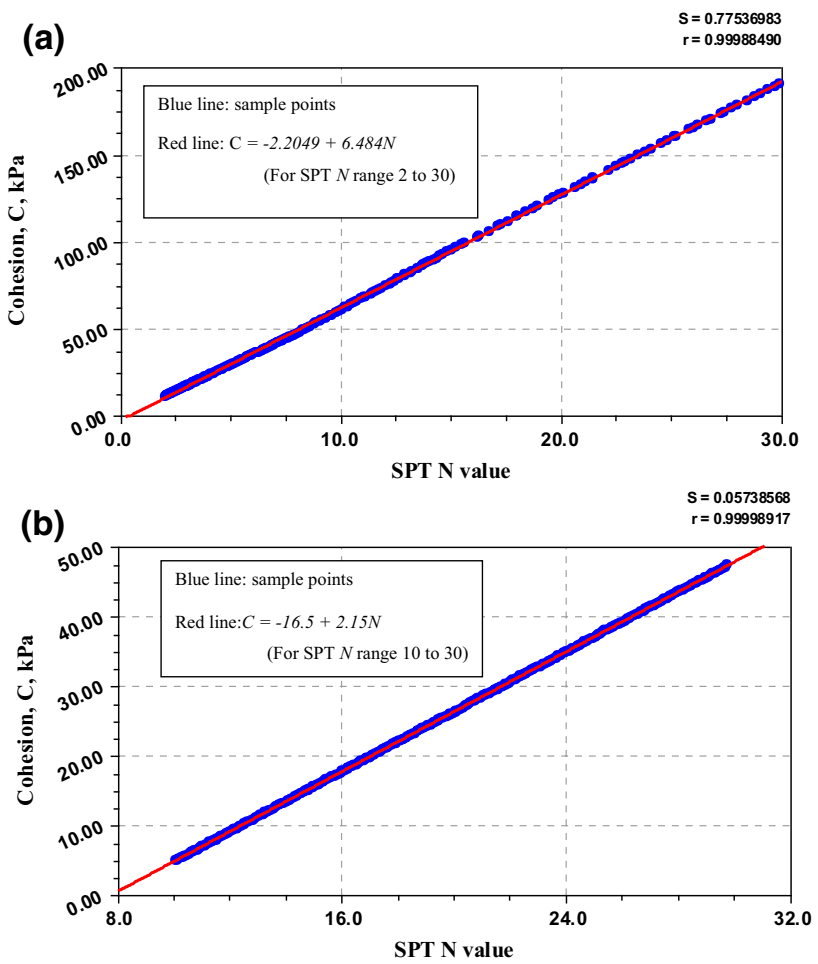

Fig. 1 a Plot of 200 pair of data points of SPT $N$ and cohesion for cohesive soils. b Plot of 300 pair of data points of SPT $N$ and cohesion for intermediate soils

other parameters can be calculated by using inter relationships. SPT $N$ value is estimated from very simple test and it is available for almost every site. This test is conducted with general soil exploration. It is very quick and inexpensive. Through random number generation technique, empirical relationships for four parameters of soils, namely shear wave velocity, Poisson's ratio, cohesion and angle of friction have been developed in terms of SPT $N$ value. Once these four parameters are obtained, the aforesaid most common input parameters for soil numerical modeling can be obtained. 
Table 3 Ranges of SPT $N$ value with angle of friction

\begin{tabular}{llllll}
\hline SPT N value & $>50$ & $30-50$ & $10-30$ & $4-10$ & $0-4$ \\
\hline Angle of friction, degree & $>41$ & $36-41$ & $30-36$ & $28-30$ & $<28$ \\
Soil conditions & Very good & Good & Fair & Poor & Very poor \\
\hline
\end{tabular}

Data from Terzhagi and Peck (1967)

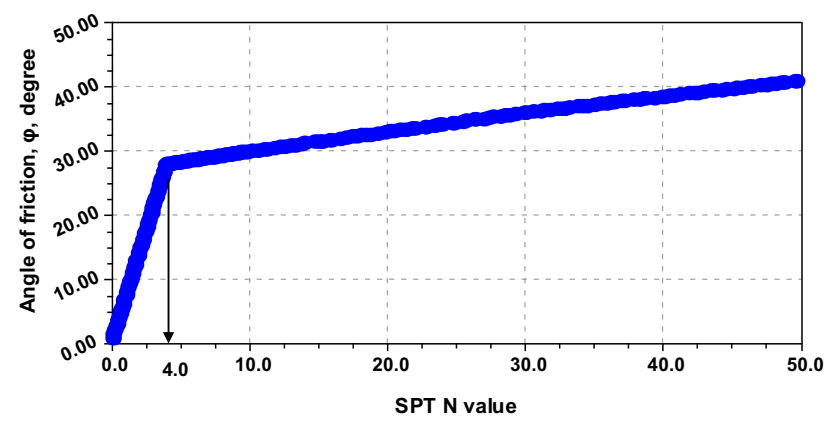

Fig. 2 Plot of 200 pair of data points of SPT $N$ value and angle of friction $\varphi$

\section{Random Number Generation by Latin Hypercube Sampling Technique (LHS) and Regression Analysis}

Random variables in the present study e.g., SPT $N$ value, cohesion, angle of friction, shear wave velocity and Poisson's ratio are sampled to represent their real distribution according to their probabilistic characteristics. As enough data is not available in literature, data are generated through random number generation technique. LHS technique (Mckay et al. 1979) is adopted as this is an inexpensive way as compared to laboratory testing. Upper and lower limits of these random variables are known and it is assumed that mean and standard deviation of these random variables are not available, hence uniform distribution is adopted.

\section{Development of Correlation Between Cohesion and SPT $\mathbf{N}$ value}

Correlation between cohesion of soil and SPT $N$ value has been given by Karol (1960) along with soil conditions representing various ranges of cohesion as given in Table 1.
It has been observed from Tables 1 and 2 that, four and one ranges of values are available for both the parameters respectively. Here, fifty and three hundred random numbers are generated for each range in Tables 1 and 2 respectively and the data are arranged in ascending order in each range. For cohesive and intermediate soils, number of data points plotted is 200 and 300 respectively as shown in Fig. 1a, b respectively and best fit curve was obtained by using CurveExpert 1.37 (Daniel 2001).

The best fit curve for cohesion of soil vs. SPT $N$ value for cohesive soils with $r^{2}$ as 0.998 is represented by following equation.

$C=-2.2049+6.484 N\left(r^{2}=0.998\right)$

where, $C$ cohesion, $\mathrm{kPa} ; N$ SPT $N$ value (range 2-30).

The best fit curve for intermediate soils with $r^{2}$ as 0.998 is represented by following equation.

$C=-16.5+2.15 N\left(r^{2}=0.998\right)$

where, $C$ cohesion, $\mathrm{kPa} ; N$ SPT $N$ value (range 10-30).

\section{Development of Correlation Between Angle of Friction and SPT $N$ value}

Ranges of angle of friction of soil with SPT $N$ value has been given by Terzhagi and Peck (1967) along with soil conditions representing various ranges of cohesion as shown in Table 3.

Initial four ranges are selected from Table 3 for development of correlation. It is observed from Table 3 that there is continuation of ranges. In the four ranges, fifty random numbers are generated for each range. The generated random numbers are arranged in ascending order in each range. In the first range, minimum value of angle of friction has been taken as zero degree. The two hundred increasingly ordered random numbers representing data
Table 4 Comparison of SPT $N$ value with shear wave velocity $V_{s}$ and Poisson's ratio

\begin{tabular}{lccc}
\hline Soil type & SPT $N$ value & Shear wave velocity, $V_{s}, \mathrm{~m} / \mathrm{s}$ & Poisson's ratio, $v$ \\
\hline Loose granular soil & $0-20$ & $130-280$ & $0.2-0.4$ \\
Dense granular soil & $20-50$ & $200-410$ & $0.3-0.45$ \\
Soft clay & $0-6$ & $40-90$ & $0.15-0.25$ \\
Stiff clay & $6-30$ & $65-140$ & $0.2-0.5$ \\
\hline
\end{tabular}

Data from Terzaghi and Peck (1967); Peck et al. (1974); Hunt (1984); Das (1994); Matasovic and Kavazanjian (1998) 
points are plotted as shown in Fig. 2 and best fit curve was obtained by using CurveExpert 1.37 (Daniel 2001). It is observed from Fig. 2 that the nature of curve changes after SPT $N$ value of 4 . Hence two correlations are proposed as follows.

The best fit curve with $r^{2}$ as 0.998 is represented by following equation.

$\varphi=7 N\left(r^{2}=0.998\right) ;$ for $N \leq 4$

$\varphi=27.12+0.2857 N\left(r^{2}=0.998\right) ;$ for $N=4$ to50

where, $\varphi=$ Angle of friction, (in degree); $N$ SPT $N$ value.

\section{Development of Correlation Between Shear Wave Velocity and SPT $N$ value}

Range of shear wave velocity, $V_{s}$ with SPT $N$ value has been prepared with the help of data given by Terzaghi and Peck (1967), Peck et al. (1974), Hunt (1984), Das (1994), Matasovic and Kavazanjian (1998) along with soil types as shown in Table 4.

It has been observed from Table 4 that different types of rocks are having different ranges of properties. There is no continuity of data in different ranges. Hence, three hundred random numbers are generated for each type of soil. The generated data are random in nature. Hence, they are arranged in ascending order in each range. Three hundred data points are plotted for each type of soil, namely loose granular soil, dense granular soil, soft clay and stiff clay as shown in Fig. 3a-d respectively and best fit curves were obtained by using CurveExpert 1.37 (Daniel 2001). The equations for best fit curves for soils with their $r^{2}$ are given in Table 5.

\section{Development of Correlation Between Poisson's Ratio and SPT $N$ value}

Ranges of Poisson's ratios, $v$ of soil and SPT $N$ value have been derived from Das (1994) along with soil types representing various ranges of $v$ as shown in Table 4. It is also observed in this table that there is no continuity of data in the ranges. Hence, three hundred random numbers are generated for each type of soil separately and the generated data are arranged in ascending order in each range. Three hundred data points are plotted for each type of soil namely, loose granular soil, dense granular soil, soft clay and stiff clay as shown in Fig. 4a-d respectively and best fit curves were obtained by using CurveExpert 1.37 (Daniel 2001). The equations for best fit curves for soils with their $r^{2}$ are given in Table 6 .

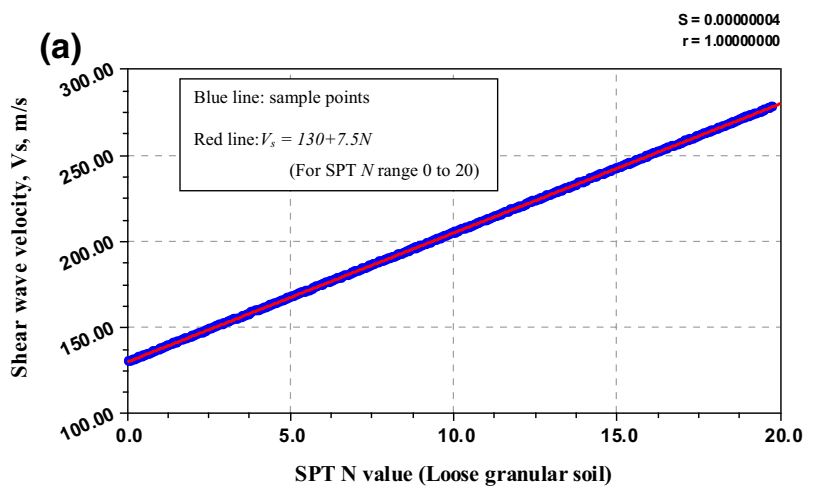

(b)

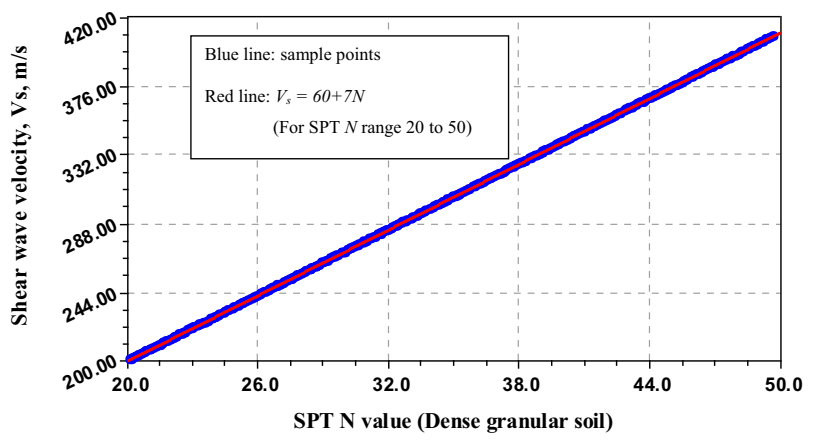

(c)

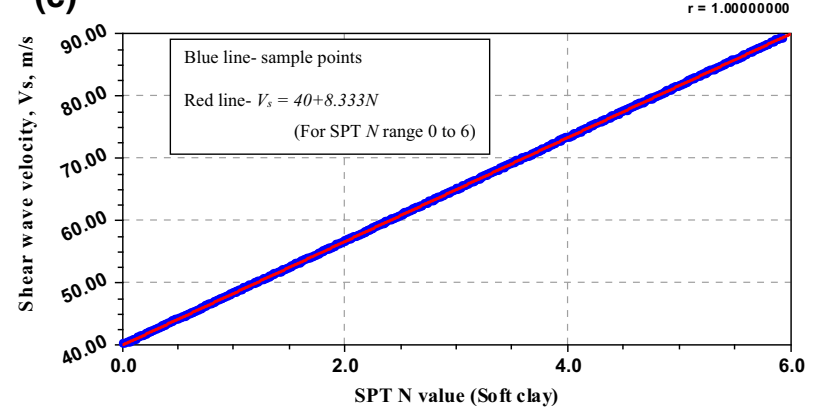

(d)

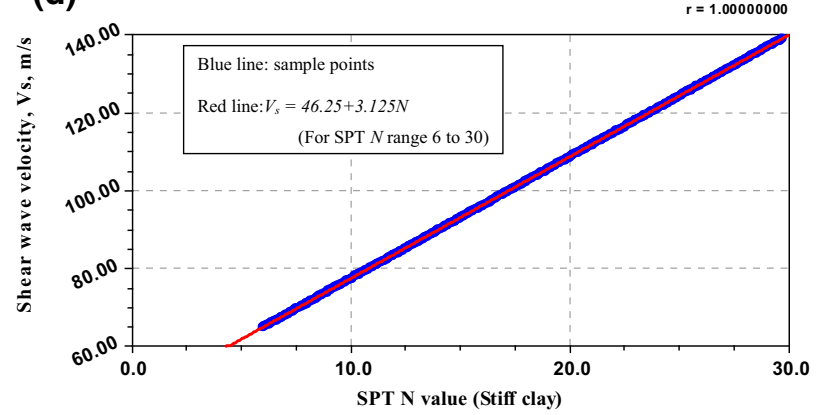

Fig. 3 a Plot of 300 pair of data points of SPT $N$ value and shear wave velocity for loose granular soil. b Plot of 300 pair of data points of SPT $N$ value and shear wave velocity for dense granular soil. $\mathbf{c}$ Plot of 300 pair of data points of SPT $N$ value and shear wave velocity for soft clay. d Plot of 300 pair of data points of SPT $N$ value and shear wave velocity for stiff clay 
Table 5 Summary of shear wave velocity and SPT $N$ value relationships

\begin{tabular}{lllc}
\hline Soil type & $\begin{array}{l}\text { Shear wave velocity, } \\
V_{s} \text { and SPT } N \text { value } \\
\text { relationship, } V_{s} \text { in } \mathrm{m} / \mathrm{s}\end{array}$ & $r^{2}$ & $\begin{array}{l}\text { Range of SPT } \\
N \text { value }\end{array}$ \\
\hline Loose granular soil & $V_{s}=130+7.5 \mathrm{~N}$ & 0.998 & $0-20$ \\
Dense granular soil & $V_{s}=60+7 \mathrm{~N}$ & 0.998 & $20-50$ \\
Soft clay & $V_{s}=40+8.333 \mathrm{~N}$ & 0.998 & $0-6$ \\
Stiff clay & $V_{s}=46.25+3.125 \mathrm{~N}$ & 0.998 & $6-30$ \\
\hline
\end{tabular}

\section{Validation of Proposed Correlation of Shear Wave Velocity with SPT $N$ values}

Experimental SPT $N$ values along with shear wave velocity are collected from literature. The developed equations in Table 5 have been validated with available experimental values in literature as shown in Fig. 5. Figure 5 presents the comparison between predicted shear wave velocity by using equations in Table 5 and experimental shear wave velocity for the observed SPT $N$ value from the recorded data. The data in figure are presented by different symbols to represent the predictions made for different experimental data. It is clear from the same figure that the deviations between the empirically predicted and the experimentally observed values are generally less than by a factor of two and this is a considerably good agreement.

\section{Validation of Proposed Correlation of Angle of Friction with Experimental Values}

Experimental SPT $N$ values along with angle of friction have been collected from literature. Equation 4 has been validated with available experimental values in literature as shown in Fig. 6. Figure 6 presents the comparison between predicted angle of friction by using Eq. 4 and experimental angle of friction for the observed SPT $N$ value from the recorded data. The data in figure are presented by different symbols to represent the predictions made for different experimental data. It is clear from the same figure that the deviations between the empirically predicted and the experimentally observed values are generally less than by a factor of two and this is a considerably good agreement.

\section{Validation of Proposed Correlations of Cohesion with Experimental Values}

Experimental SPT $N$ values along with cohesion have been collected from literature. Equation 2 has been validated with available experimental values in literature as shown in Fig. 7. This figure presents the comparison between predicted cohesion by using Eq. 2 and experimental cohesion for the observed SPT N value from the recorded data. The
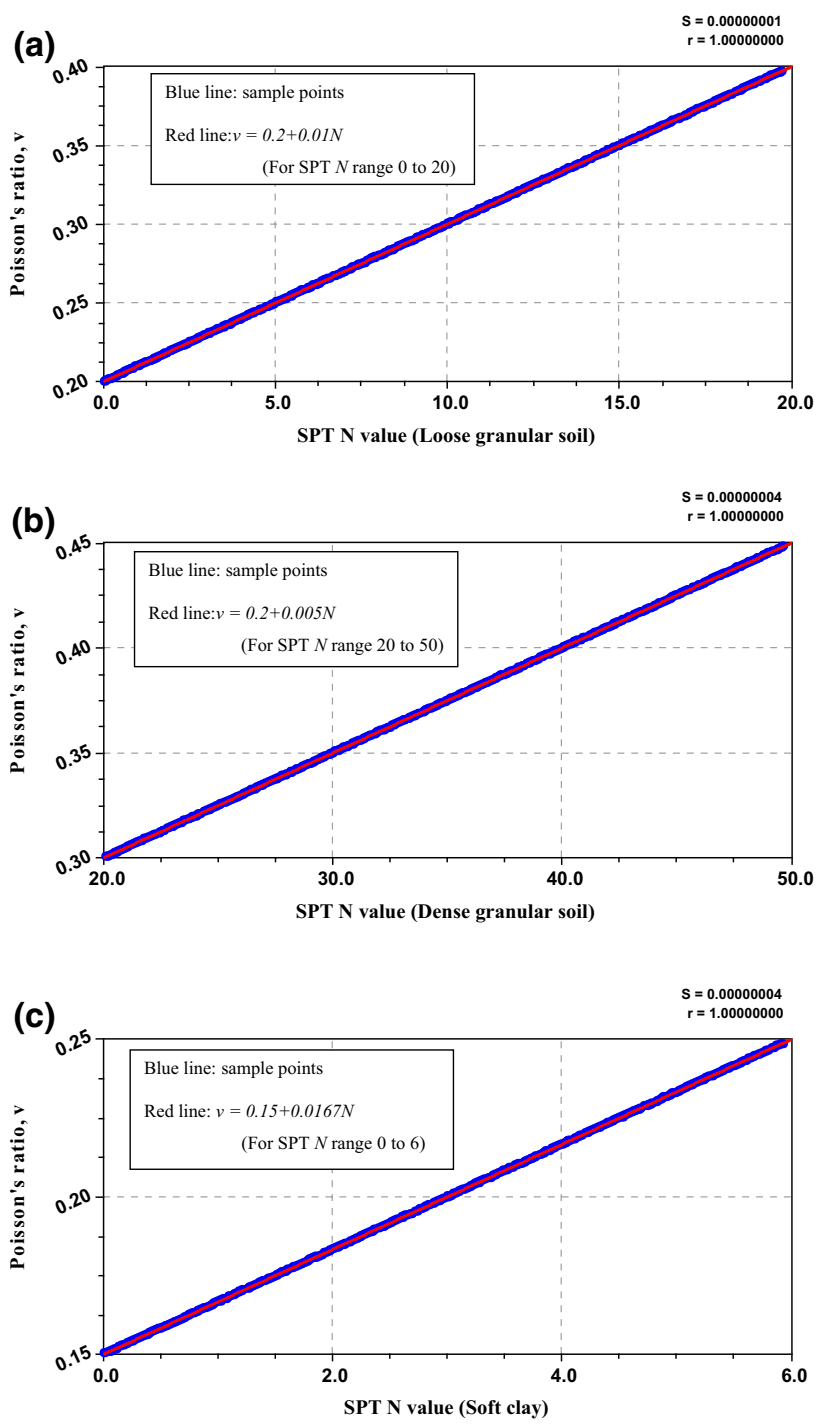

(d)

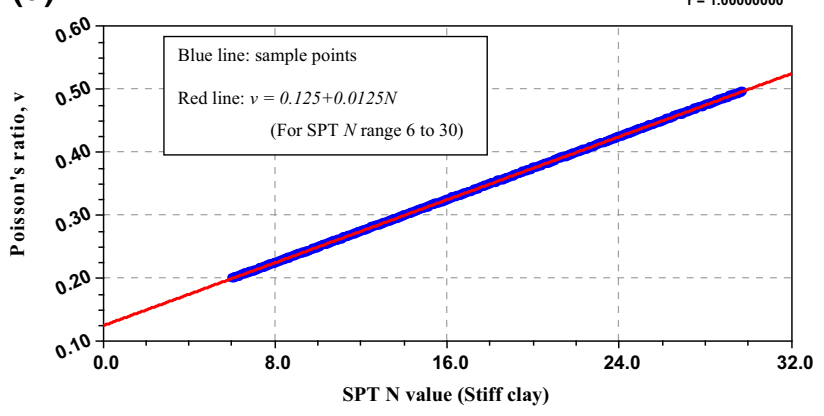

Fig. 4 a Plot of 300 pair of data points of SPT $N$ value and Poisson's ratio for loose granular soil. b Plot of 300 pair of data points of SPT $N$ value and Poisson's ratio for dense granular soil. c Plot of 300 pair of data points of SPT $N$ value and Poisson's ratio for soft clay. d Plot of 300 pair of data points of SPT $N$ value and Poisson's ratio for stiff clay

data from one literature is obtained. It is clear from the same figure that the deviations between the empirically predicted and the experimentally observed values are 
Table 6 Summary of Poisson's ratio, $v$ and SPT $N$ value relationships

\begin{tabular}{llcc}
\hline Soil type & $v$ and SPT $N$ value relationship & $r^{2}$ & Range of $N$ \\
\hline Loose granular soil & $v=0.2+0.01 N$ & 0.998 & $0-20$ \\
Dense granular soil & $v=0.2+0.005 N$ & 0.998 & $20-50$ \\
Soft clay & $v=0.15+0.0167 N$ & 0.998 & $0-6$ \\
Stiff clay & $v=0.125+0.0125 N$ & 0.998 & $6-30$ \\
\hline
\end{tabular}

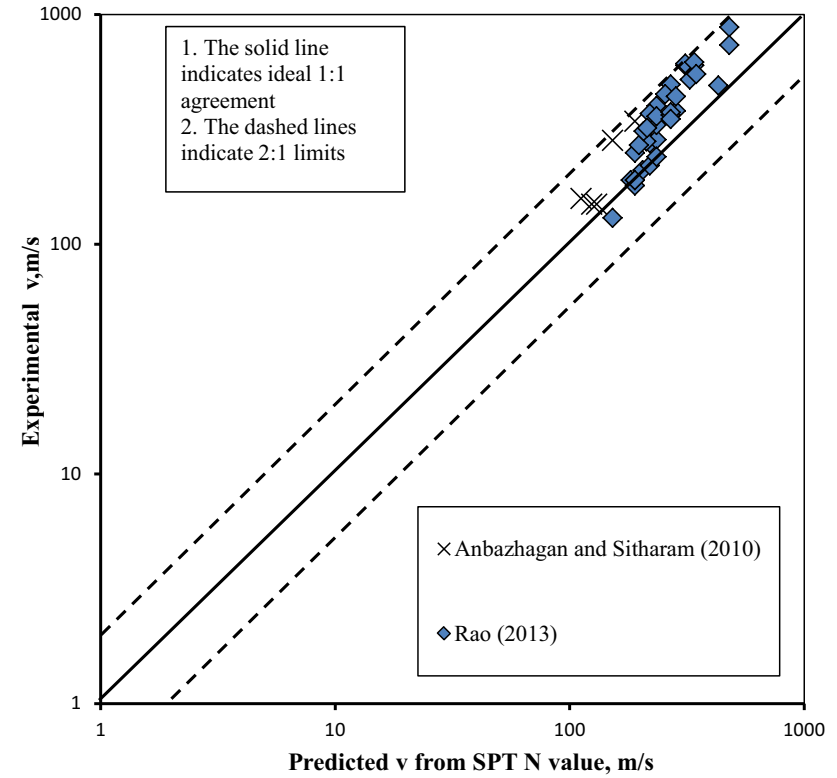

Fig. 5 Comparison between experimental shear wave velocity, $v$ and predicted shear wave velocity, $v$ using proposed empirical model in present study

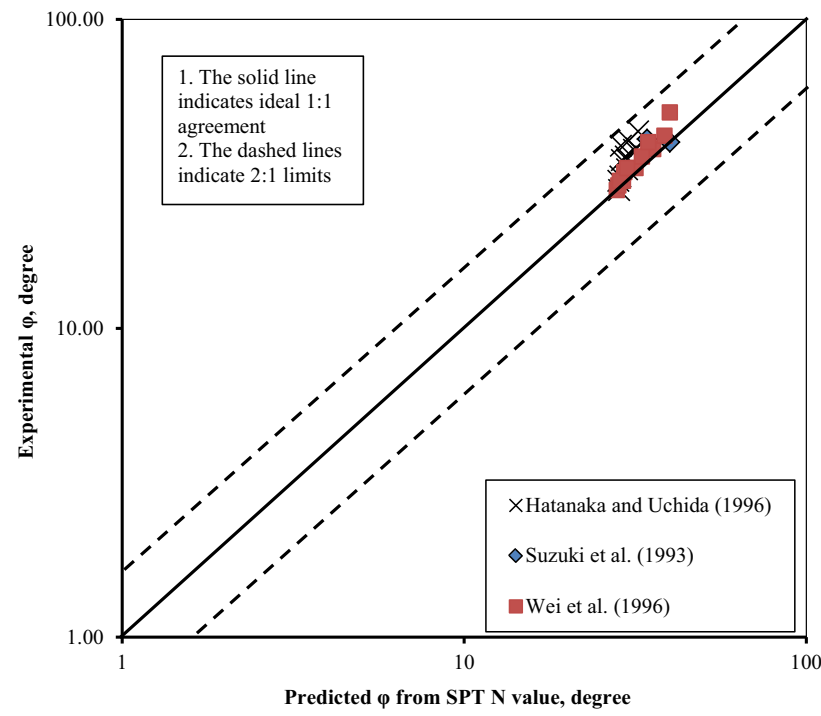

Fig. 6 Comparison between experimental $\varphi$ and predicted $\varphi$ using proposed empirical model in present study

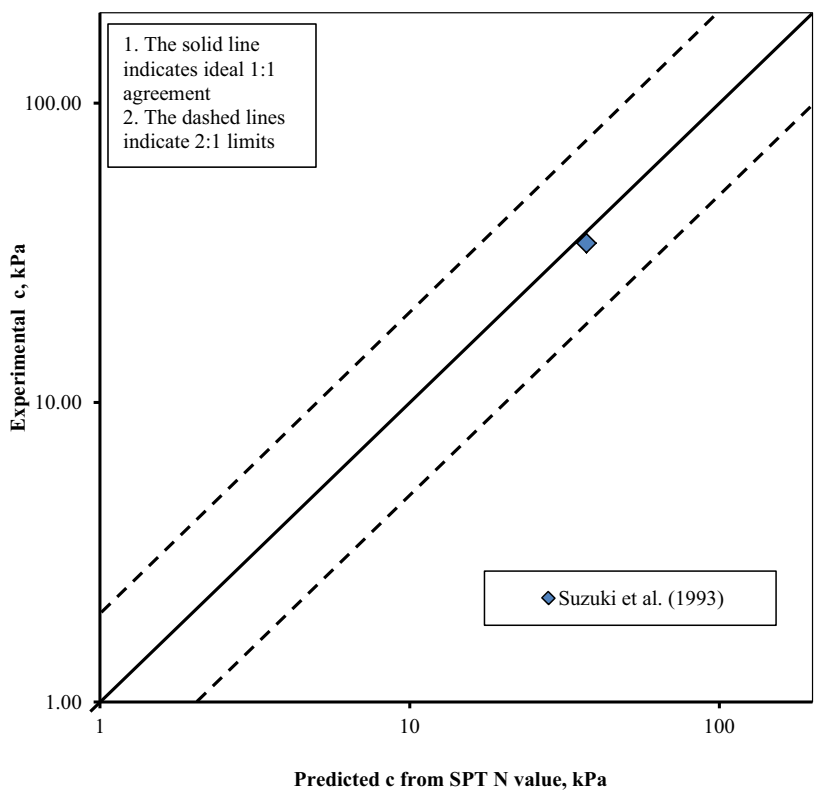

Fig. 7 Comparison between experimental $E$ and predicted $E$ for limestone using proposed empirical model in present study

generally less than by a factor of two and this is a considerably good agreement.

\section{Conclusions}

SPT is one of the most effective and common tests used for quick and inexpensive estimation of mechanical properties of soil. Correlation of cohesion, angle of friction, shear wave velocity and Poisson's ratio of soils in terms of SPT $N$ value have been established through random number generation technique. In case of cohesion, typical values are available for two types of soils namely cohesive and intermediate soils. The ranges of values for both types of soils are totally different. Hence, two different relationships for cohesion for broadly two types of soils are proposed. In case of angle of friction, even if typical values are available for soil, sudden change in the nature of plot of randomly generated data is observed. Due to this sudden change in plot, two different 
relationships for angle of friction are proposed for different ranges of SPT $N$ value. In case of shear wave velocity and Poisson's ratio, four different ranges of typical values for both are available which are discontinuous. Hence, four different relationships each for shear wave velocity and Poisson's ratio are proposed for broadly four types of soil. The results of regression analysis show maximum correlation coefficient and minimum standard error. The proposed relationships have been validated with the help of experimental data available in literature. The usefulness of random number generation technique is established for development of correlations. The equations available in the literature by various authors may be used in practice for specific soil types only. With the help of single soil parameter only, namely SPT $N$ value, the present correlations will be very useful for practicing engineers to estimate the relevant soil input parameters for numerical modeling of foundation in soil subjected to blast. These equations are simple, practical and accurate enough which can be used for any types of soils with acceptable accuracy. The present correlations can be used with acceptable accuracy at the preliminary stage of design. The results of present study will also be useful for a range of geo-mechanical problems such as stability analysis, in situ stress measurements etc. without direct strength information available.Statistical analysis shows that the present correlations provide better estimation of mechanical properties.

\section{References}

Akin MK, Kramer SL, Topal T (2011) Empirical correlations of shear wave velocity $\left(\mathrm{V}_{\mathrm{s}}\right)$ and penetration resistance (SPT-N) for different soils in an earthquake prone area (Erbaa-Turkey). Eng Geol 119:1-17

Anbazhagan P, Sitharam TG (2010) Relationship between low strain shear modulus and standard penetration test $\mathrm{N}$ values. Geotech Test J 33(2):1-15

Anbazhagan P, Parihar A, Rashmi HN (2012) Review of correlations between SPT N and shear modulus: a new correlation applicable to any region. Soil Dyn Earthq Eng 36:52-69

Anbazhagan P, Kumar A, Sitharam TG (2013) Seismic site classification and correlation between standard penetration test $\mathrm{N}$ value and shear wave velocity for Lucknow city in IndoGangetic basin. Pure appl Geophys 170:299-318

Brown T, Hettiarachchi H (2008) Estimating shear strength properties of soils using SPT blow counts: an energy balance approach. In: Alshawabkeh AN, Reddy KR, Khire MV (eds) GeoCongress 2008: characterization, monitoring, and modeling of geosystems, New Orleans, Louisiana, USA, 9-12 March 2008. American Society of Civil Engineers, pp 364-371. doi:10.1061/40972(311)46

Chatterjee K, Choudhury D (2013) Variations in shear wave velocity and soil site class in Kolkata city using regression and sensitivity analysis. Nat Hazards 69:2057-2082
Daniel (2001) CurveExpert 1.37 (evaluation copy). http://curveexpert. webhop.biz/. Accessed 23 Dec 2014

Das BM (1994) Principles of Geotechnical Engineering. PWS Publishing Company

Hara A, Ohta T, Niwa M, Tanaka S, Banno T (1974) Shear modulus and shear strength of cohesive soils. Soils Found 14(3):1-12

Hasancebi N, Ulusay R (2007) Empirical correlations between shear wave velocity and penetration resistance for ground shaking assessments. Bull Eng Geol Environ 66:203-213

Hatanaka M, Uchida A (1996) Empirical correlation between penetration resistance and internal friction angle of sandy soils. Soils Found 36(4):1-9

Hettriarachchi H, Brown T (2009) Use of SPT blow counts to estimate shear strength properties of soils: energy balance approach. J Geotech Geo Environ Eng ACSE 135:830-834

Hunt RE (1984) Geotechnical engineering investigation manual. McGrawHill, NewYork

Kalantary F, Ardalan H, Nariman-Zadeh N (2009) An investigation on the $\mathrm{S}_{\mathrm{u}}-\mathrm{N}_{\mathrm{SPT}}$ correlation using GMDH type neural networks and genetic algorithms. Eng Geol 104:144-155

Karol RH (1960) Soils and soil engineering. Prentice Hall, Eaglewood Cliffs

Kumar R, Choudhury D, Bhargava K (2012) Response of foundations subjected to blast loadings: state of the art review. Disaster Adv 5(1):54-63

Kumar R, Choudhury D, Bhargava K (2014a) Prediction of blast induced vibration parameters for soil sites. Int J Geomech ASCE 14(3): $1-10$

Kumar R, Choudhury D, Bhargava K (2014b) Response of shallow foundation in rocks subjected to underground blast loading using FLAC3D. Disaster Adv 7(2):64-71

Kumar R, Choudhury D, Bhargava K (2015) Simulation of rock subjected to underground blast using FLAC3D, Japanese Geotechnical Society Special Publication. In section 1. Characterization-rock and expansive soil, The 15th Asian Regional Conference on Soil Mechanics and Geotechnical Engineering, Japan, 2(12):508-511. doi:10.3208/jgssp.IND-27

Kumar R, Choudhury D, Bhargava K (2016a) Determination of blast induced ground vibration equations for rocks using mechanical and geological properties. J Rock Mech Geotech Eng. doi:10. 1016/j.jrmge.2015.10.009

Kumar R, Bhargava K, Choudhury D (2016b) Correlations of uniaxial compressive strength of rock mass with conventional strength properties through random number generation. Int $\mathrm{J}$ Geomech ASCE (accepted, in press for publication)

Maheswari RU, Boominathan A, Dodagoudar GR (2010) Use of surface waves in statistical correlations of shear wave velocity and penetration resistance of Chennai soils. Geotech Geol Eng 28:119-137

Matasovic N, Kavazanjian E Jr. (1998) Cyclic characterisation of oil landfill solid waste. J Geotech Geoenviron Eng ASCE 124(3): 197-210

Mckay MD, Bechman RJ, Conover WJ (1979) A comparison of three methods for selecting values of input variables in the analysis of output from a computer code. Techno metrics 21(2):239-245

Miura S, Yagi K, Asonuma T (2003) Deformation strength evaluation of crushable volcanic soils by laboratory and in situ testing. Soils Found 43(4):47-57

Peck RB, Hanson WE, Thornburn TH (1974) Foundation engineering, 2nd edn. Wiley \& Sons Inc., New York

Rao CS (2013) Estimation of shear wave velocity from soil indices. Indian Geotech J 43(3):267-273

Sivrikaya O, Togrol E (2006) Determination of undrained strength of fine grained soils by means of SPT and its application in Turkey. Eng Geol 86:52-69 
Sun CG, Cho CS, Son M, Shin JS (2013) Correlations between shear wave velocity and in situ penetration test results for Korean soil deposits. Pure appl Geophys 170:271-281

Suzuki Y, GotoS Hatanaka M, Tokimatsu K (1993) Correlation between strengths and penetration resistances for gravelly soils. Soils Found 33(1):92-101
Terzaghi K, Peck RB (1967) Soil mechanics in engineering practice, 2nd edn. Wiley, New York

Wei BZ, Pezeshk S, Chang TS, Hall KH, Liu HP (1996) An empirical method to estimate shear wave velocity of soils in the New Madrid seismic zone. Soil Dyn Earthq Eng 15:399-408 